\title{
KHẢO SÁT GIÁ TRİ CỦA FRUCTOSAMINE HUYẾT THANH TRONG THEO DÕI ĐIỀU TRI BỆNH NHÂN ĐÁI THÁO ĐƯờNG TYP 2 CAO TUỔI TẠI BỆNH VIỆN HỮU NGHI
}

\author{
Lường Trọng Bách¹, Đỗ Trung Quân², Nguyễn Thị Thanh Thủy ${ }^{3}$
}

\section{TÓM TẮT}

Fructosamin (FA) là sản phẩm albumin bị glycosyl hóa. Cũng giống như $\mathrm{HbA1C}$, glucose gắn vào albumin theo tỷ lệ thuận và một khi đã gắn vào thì không thể tách rời trở lại được. Thời gian tồn tại của FA gắn liền với thời gian bán hủy của albumin trong cơ thể khoảng 12 - 20 ngày. Chính vì vậy fructosamin cũng được sử dụng để đánh giá kiểm soát glucose máu của bệnh nhân với ưu điểm trong khoảng thời gian 2-3 tuần, phù hợp cho việc đánh giá glucose máu của bệnh nhân trong giai đoạn ngắn, nồng độ glucose máu thay đổi nhanh, nồng độ glucose máu thay đổi nhanh, trong giai đoạn bệnh nhân được điều trị nội trú tại bệnh viện, đắc biệt ở những bệnh nhẩn đái tháo đường cao tuổi cũng như những bểnh nhân có rối loạn huyết động và các bệnh lý về máu. Mục tiêu: Khảo sát giá trị Fructosamin huyết thanh trong kiểm soát đường huyết ở bệnh nhân ĐTĐ typ2 tại Bệnh viện hữu nghị. Đối tượng và phương pháp nghiên cứu: nghiên cứu mô tả cắt ngang, tiến cứu Đối tượng nghiên cứu gồm 50 bênh nhân được chẩn đoán xác định đái tháo đường typ2, từ 60 tuổi trở lên. Từ tháng $8 / 2020$ đến tháng 8/2021. Kết quả: Nồng độ glucose máu lúc đói, sau ăn, trung bình của các đối tượng nghiên cứu giảm nhiếu trong thời gian nằm viên điều trị. Sự khác biệt trung bình của glucose máu lúc đói, sau ăn, trung bình lúc vào viện và ra viên tương ứng $9,0 \mathrm{mmol} / \mathrm{L}, 4,7 \mathrm{mmol} / \mathrm{L}, 6,8 \mathrm{mmol} / \mathrm{L}$ và đều có ý nghĩa thông kê ở ngưỡng xác suất $p<0,0001$. Tỳ lệ đối tượng nghiên cứu đạt mục tiêu kiểm soát glucose máu lúc đói tăng rõ rệt sau thời gian nằm viện điều trị. Khi vào viện có $0 \%$ số đối tượng nghiên cứu có mức glucose máu lúc đói đạt mục tiêu kiểm soát glucose máu lúc đói, khi ra viện có $36,0 \%$ đối tượng nghiên cứu đạt mục tiêu kiểm soát glucose máu lúc đói. Tỷ lệ đối tượng nghiên cứu đạt mục tiêu kiểm soát glucose máu sau ăn tăng nhiều sau thời gian nằm viện. Tỷ lệ đạt muc tiêu glucose máu sau ăn từ $12,0 \%$ khi vào viện tăng lên $68,0 \%$ khi bệnh nhân ra viện. Trong số những đối tượng nghiên cứu chưa đạt mục tiêu kiểm soát glucose máu, nồng độ glucose máu khi ra viện được cải thiện nhiều so với khi vào viện. Sự khác biệt trung bình giữa glucose máu trước và sau điêu trị lúc đói là $9,0 \mathrm{mmol} / \mathrm{L}$, sau ăn là $5,4 \mathrm{mmol} / \mathrm{L}$ (giá trị $\mathrm{p}$ tương ứng đều thấp hơn 0,0001). Giá trị fructosamin trung

\footnotetext{
${ }^{1}$ Bệnh viện đa khoa tỉnh Sơn La

${ }^{2}$ Trường Đại học Y Hà Nội

33eênh viện hữu nghi Việt Xô

Chịu trách nhiệm chính: Lường Trọng Bách

Email: drbach90@gmail.com

Ngày nhận bài: 2.8.2021

Ngày phản biện khoa học: 28.9.2021

Ngày duyệt bài: 5.10.2021
}

bình khi ra viên thấp hơn nhiều khi vào viện trung bình $68,7 \mu \mathrm{mol} / \mathrm{L}(360,6 \pm 69,9 \mu \mathrm{mol} / \mathrm{L}$ so với $429,3 \pm$ $62,2 \mu \mathrm{mol} / \mathrm{L})$ có ý nghĩ thống kê với $\mathrm{p}<0,0001$. Kết luân: Theo dõi giá tri fructosamin huyết thanh trong đợt $B N$ điều trị nội trú có thể đánh giá hiệu quả điều trị trong khi HbA1C không có giá trị trong đánh giá giai đoạn điều trị ngắn

Tứ Khóa: Fructosamin, Đái tháo đường type2, Glucose, HbA1c, chẩn đoán

\section{SUMMARY}

\section{SURVEY VALUE OF FRUCTOSAMINE SERUM IN MONITORING AND TREATMEANT PATIENTS OLD AGE DIABETES TYPE 2 AT THE HUU NGHI HOSPITAL}

Fructosamine (FA) is a glycosylated albumine product. Like $\mathrm{HbA1C}$, glucose binds to albumine in a proportional manner and, once attached, cannot be separated again. The lifetime of FA is associated with the half-life of albumine in the body of about 20 days. Therefore, fructosamine is also used to assess the patient's blood glucose control with the advantage of a 2-3 week period, suitable for assessing the patient's blood glucose in a short period of time, blood glucose concentration rapidly changing blood glucose levels, during the inpatient period of the hospital, especially in elderly diabetic patients as well as in patients with hemodynamic disorders and other diseases. blood theory. Aims: To investigate the value of serum fructosamine in blood sugar control in patients with type 2 diabetes at huu nghi Hospital. Methods: a cross-sectional, prospective study The study population included 50 patients with confirmed diagnosis of type 2 diabetes, aged 60 years and older. From February 2021 to August 2021. Result: The average fasting, postprandial blood glucose concentration of the study subjects decreased significantly during the hospital stay. The mean difference of fasting, postprandial, mean at hospital admission and discharge, respectively $9.0 \mathrm{mmol} / \mathrm{L}, 4.7$ $\mathrm{mmol} / \mathrm{L}, 6.8 \mathrm{mmol} / \mathrm{L}$ and were all significant. listed at the threshold of probability $p<0.0001$. The percentage of study subjects who achieved the goal of fasting blood glucose control increased significantly after the hospital stay. At hospital admission, $0 \%$ of the study subjects had fasting blood glucose levels that reached the fasting blood glucose control target, and at discharge, $36.0 \%$ of the study subjects reached the fasting blood glucose control target. The percentage of study subjects who achieved the goal of controlling blood glucose after meals increased significantly after the hospital stay. The rate of achieving the goal of postprandial blood glucose increased from $12.0 \%$ upon admission to $68.0 \%$ when the patient was discharged. Among the study subjects 
who did not achieve the goal of blood glucose control, the blood glucose concentration at hospital discharge was much improved compared to when admitted to the hospital. The mean difference between blood glucose before and after fasting treatment was 9.0 $\mathrm{mmol} / \mathrm{L}$, after eating was $5.4 \mathrm{mmol} / \mathrm{L}$ (respective $\mathrm{p}$ values were all lower than 0.0001). The mean fructosamine value at hospital discharge was much lower than that at hospital admission, with an average of $68.7 \mu \mathrm{mol} / \mathrm{L}(360.6 \pm 69.9 \mu \mathrm{mol} / \mathrm{L}$ versus $429.3 \pm$ $62.2 \mu \mathrm{mol} / \mathrm{L}$ ) which was statistically significant with $\mathrm{p}$ $<0.0001$. Conclusion: Proportion of patients reaching treatment goals through fasting glucose index and fructosamine was $36.0 \%$ and $30.0 \%$, respectively. Kappa coefficient is 0.7748 (highly agree) - Average glucose in fasting, 2 hours after eating, average and fructosamine decreased by $9.0 \pm$ $4.4 \mathrm{mmol} / \mathrm{L}$, respectively; $4.7 \pm 4.3 \mathrm{mmol} / \mathrm{L} ; \quad 6.8 \pm$ $3.3 \mathrm{mmol} / \mathrm{L} ;$ and $68.7 \pm 90.2 \mathrm{~mol} / \mathrm{l}$. - The mean fructosamine value at hospital discharge was much lower than that at hospital admission, with an average of $68.7 \mu \mathrm{mol} / \mathrm{L}(360.6 \pm 69.9 \mu \mathrm{mol} / \mathrm{L}$ versus $429.3 \pm$ $62.2 \mu \mathrm{mol} / \mathrm{L})$ with statistical significance. with $\mathrm{p}<$ 0.0001 . - On admission, $100 \%$ of patients did not achieve the goal of blood sugar control based on the fructosamin index

Keywords: Fructosamine, Type 2 diabetes, Glucose, HbA1c, diagmosis

\section{I. ĐĂT VẤN ĐỀ}

Trước đây, việc kiểm soát rối loạn chuyển hóa ở bệnh nhân ĐTĐ chủ yếu dựa vào xét nghiệm glucose máu và nước tiểu. Tuy nhiên, những xét nghiệm này chỉ phản ánh trạng thái glucose máu và đường niệu ở thời điểm chỉ định, điều này sẽ không có giá trị đối với việc theo dõi và kiểm soát chuyển hóa glucose trong thời gian dài. Từ những thập niên 1970 với sự ra đời của xét nghiệm HbA1c và 1980 với sự ra đời của xét nghiệm fructosamin đã mang lại những tiến bộ mới trong theo dõi và kiểm soát glucose máu.

Hemoglobin A1C (HbA1c) là một trị số thường được sử dụng để theo dõi, đánh giá nông độ glucose máu trung bình ở bệnh nhân ĐTĐ trong khoảng thời gian 2 - 3 tháng trước khi xét nghiệm. Mục tiêu điều trị bệnh ĐTĐ là đạt được trị số $\mathrm{HbA} 1 \mathrm{c}<7 \%$ và càng gân trị số bình thường càng tốt (4-6\%) mà không gây hạ glucose máu. Một số trường hợp bệnh nhân có tiền sử hạ glucose máu, người già, phụ nữ mang thai, hoặc một số trường hợp bệnh lý kèm theo

\section{KẾT QUẢ NGHIÊN CứU}

3.1. Hiệu quả kiểm soát đường máu thông qua chỉ số glucose và fructosamin

3.3.1. Hiệu quả điều trị dưa vào glucose máu trước và sau điều trị

Bảng 3.1. So sánh nông độ glucose máu trước và sau điều trị

\begin{tabular}{|c|c|c|c|c|}
\hline & Trước đîêu trị & Sau điều trị & Khác biệt & \\
\hline & (mmol/L) & (mmol/L) & (mmol/L) & $G$ \\
\hline Glucose đói & $16,4 \pm 4,8$ & $7,3 \pm 1,3$ & $9,0 \pm 4,4$ & $<0,0001$ \\
\hline
\end{tabular}

như rối loạn huyết động, thiếu máu do thiếu sắt, mất máu, tan máu; bệnh hồng câu liềm thì HbA1C không phản ảnh chính xác tình trạng glucose máu của bệnh nhân. Ngoài ra, HbẢ1c không thích hợp để đánh giá thay đổi glucose máu trong một khoảng thời gian ngắn hơn (2-3 tuân).

Fructosamin (FA) là sản phẩm albumin bị glycosyl hóa. Cũng giống như HbA1c, glucose gắn vào albumin theo tỷ lệ thuận và một khi đã gắn vào thì không thể tách rời trở lại được. Thời gian tôn tại của FA gắn liền với thời gian bán hủy của albumin trong cơ thể khoảng 12 đến 20 ngày. Chính vì vậy fructosamin cũng được sử dụng để đánh giá kiểm soát glucose máu của bệnh nhân với ưu điểm trong khoảng thời gian 2-3 tuân, phù hợp cho việc đánh giá glucose máu của bệnh nhân trong giai đoạn ngắn, nồng độ glucose máu thay đổi nhanh, nồng độ glucose được điêu trị nội trú tại bệnh viện, đặc biệt ở những bệnh nhân ĐTĐ cao tuổi cũng như những bệnh nhẩn có rối loạn huyết động và các bệnh lý vể máu. Chính vì vậy chúng tôi tiến hành nghiên cứu đề tài.

\section{II. ĐỐI TƯợNG VÀ PHƯƠNG PHÁP NGHIÊN CỨU}

2.1 Đối tượng nghiên cứu. gôm $50 \mathrm{BN}$ ĐTĐ typ 2 tại BV hữu nghị từ tháng 8/2020 đến tháng 8/2021

\subsection{Phương pháp nghiên cứu:}

Thiết kế nghiên cứu: cắt ngang, tiến cứu

- Nội dung nghiên cứu:

- Tuổi, giới

- Đắc điểm lâm sàng: Đái tháo đường theo tiêu chuẩn của bộ y tế 2020. Số năm được chẩn đoán đái tháo đường, các triệu chứng lâm sàng của đái tháo đường lúc vào viện, các biến chứng đái tháo đường kèm theo.

Cận lâm sàng: Fructosamin ngày đâu vào viện, glucose máu lúc đói, Hba1c lúc vào viện, protein, albumin, Điện giải đồ, Mg, cholesterol, triglycerid, creatinin, ure, acid uric, TSH, FT4, cortisol máu siêu âm ổ bụng, siêu âm doppler mạch chi dưới, siêu âm doppler tim, siêu âm tuyến giáp

2.3 Xử lí số liệu: Phân mềm IBM SPSS Statistics 20. máu thay đổi nhanh, trong giai đoạn bệnh nhân 


\begin{tabular}{|c|c|c|c|c|}
\hline Glucose sau ăn & $14,2 \pm 3,6$ & $9,5 \pm 1,8$ & $4,7 \pm 4,3$ & $<0,0001$ \\
\hline Glucose tb & $15,3 \pm 3,4$ & $8,4 \pm 1,3$ & $6,8 \pm 3,3$ & $<0,0001$ \\
\hline
\end{tabular}

Nhận xét: Nồng độ glucose máu lúc đói, sau ăn, trung bình của các đối tượng nghiên cứu giảm nhiều trong thời gian nằm viện điều trị. Sự khác biệt trung bình của glucose máu lúc đói, sau ăn, trung bình lúc váo viện và ra viện tương ứng $9,0 \mathrm{mmol} / \mathrm{L}, 4,7 \mathrm{mmol} / \mathrm{L}, 6,8 \mathrm{mmol} / \mathrm{L}$ và đều có ý nghĩa thông kê ở ngưỡng xác suất $\mathrm{p}<0,0001$.

Bảng 3.2. Giá trị fructosamin trung bình trước và sau điều trị

\begin{tabular}{|c|c|c|c|c|}
\hline Chỉ số & $\begin{array}{c}\text { Trước điều trị } \\
(\boldsymbol{\mu m o l} / \mathbf{L})\end{array}$ & $\begin{array}{c}\text { Sau điều trị } \\
(\boldsymbol{\mu m o l} / \mathbf{L})\end{array}$ & $\begin{array}{c}\text { Khác biệt } \\
(\boldsymbol{\mu m o l} / \mathbf{L})\end{array}$ & $\begin{array}{c}\text { Giá trị } \\
\mathbf{p}\end{array}$ \\
\hline Fructosamin & $429,3 \pm 62,2$ & $360,6 \pm 69,9$ & $68,7 \pm 90,2$ & $<0,0001$ \\
\hline
\end{tabular}

Nhận xét: Giá trị fructosamin trung bình khi ra viện thấp hơn nhiều khi vào viện trung bình 68,7

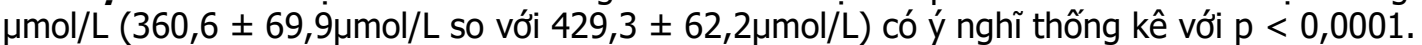

Bảng 3.3. So sánh glucose máu lúc đói và sau ăn của những đôi tượng không đạt mục tiêu điều trị

\begin{tabular}{|c|c|c|c|c||}
\hline Chỉ số (n) & $\begin{array}{c}\text { Trước điêu trị } \\
\text { (mmol/L) }\end{array}$ & $\begin{array}{c}\text { Sau điêu trị } \\
\text { (mmol/L) }\end{array}$ & $\begin{array}{c}\text { Khác biệt } \\
\text { (mmol/L) }\end{array}$ & Giá trị p \\
\hline Glucose đói $(n=50)$ & $16,4 \pm 4,8$ & $7,3 \pm 1,3$ & $9,0 \pm 4,4$ & $<0,0001$ \\
\hline Glucose sau ăn(n=44) & $15,0 \pm 3,0$ & $9,6 \pm 1,8$ & $5,4 \pm 4,1$ & $<0,0001$ \\
\hline
\end{tabular}

Nhận xét: Trong số những đối tượng nghiên cứu chưa đạt mục tiêu kiếm soát glucose máu, nồng độ glucose máu khi ra viện được cải thiện nhiều so với khi vào viện. Sự khác biệt trung bình giữa glucose máu trước và sau điêu trị lúc đói là $9,0 \mathrm{mmol} / \mathrm{L}$, sau ăn là $5,4 \mathrm{mmol} / \mathrm{L}$ (giá trị $\mathrm{p}$ tương ứng đều thấp hơn 0,0001).

Bảng 3.4. Tỷ lệ đôî tương nghiên cứu đạt muc tiêu kiểm soát glucose đói

\begin{tabular}{|c|c|c|c|c|c|}
\hline \multicolumn{2}{|c|}{ Biến số } & \multicolumn{4}{|c|}{ Phân bố glucose máu lúc đói ra viện } \\
\hline \multirow{5}{*}{$\begin{array}{c}\text { Phân bố } \\
\text { glucose } \\
\text { máu lúc } \\
\text { đói } \\
\text { vào viên }\end{array}$} & & Tối ưu & Đat & Không đạt & Tổng số \\
\hline & Tối ưu & 0 & 0 & 0 & 0 \\
\hline & Đạt & 0 & 0 & 0 & 0 \\
\hline & Không đạt & $4(8 \%)$ & $14(28 \%)$ & $32(64 \%)$ & $50(100 \%)$ \\
\hline & Tổng số & $4(8 \%)$ & $14(28 \%)$ & $32(64 \%)$ & $50(100 \%)$ \\
\hline
\end{tabular}

Nhận xét: Tỷ lệ đối tượng nghiên cứu đạt mục tiêu kiểm soát glucose máu lúc đói tăng rõ rêt sau thời gian nằm viện điều trị. Khi vào viên có $0 \%$ số đối tượng nghiên cứu có mức glucose máu lúc đói đạt mục tiêu kiểm soát glucose máu lúc đói, khi ra viện có $36,0 \%$ đối tượng nghiên cứu đạt mục tiêu kiểm soát glucóe máu lúc đói.

Bảng 3.5. Tỷ lệ đối tượng nghiên cứu đạt mục tiêu kiểm soát glucose sau ăn

\begin{tabular}{|c|c|c|c|c|c|}
\hline \multicolumn{2}{|c|}{ Biến số } & \multicolumn{4}{c|}{ Phân bố glucose máu sau ăn ra viện } \\
\cline { 2 - 6 } & Tối ưu & Đạt & Không đạt & Tống số \\
\hline \multirow{2}{*}{$\begin{array}{c}\text { Phân bố } \\
\text { glucose } \\
\text { sau ăn vào } \\
\text { viên }\end{array}$} & Tối & $3(75 \%)$ & $1(35 \%)$ & 0 & $4(8 \%)$ \\
\cline { 2 - 6 } & Đạt & 0 & $1(50 \%)$ & $1(50 \%)$ & $2(4 \%)$ \\
\cline { 2 - 6 } & Không đạt & $9(20,5 \%)$ & $20(45,4 \%)$ & $15(34,1 \%)$ & $44(88 \%)$ \\
\cline { 2 - 6 } & Tống số & $12(24 \%)$ & $22(44 \%)$ & $16(32 \%)$ & $50(100 \%)$ \\
\hline
\end{tabular}

Nhân xét: Tỷ lệ đối tượng nghiên cứu đạt mục tiêu kiếm soát glucose máu sau ăn tăng. Nhiều sau thời gian nằm viện. Tỷ lệ đạt mục tiêu glucose máu sau ăn từ $12,0 \%$ khi vào viện tăng lên $68,0 \%$ khi bệnh nhân ra viện.

Bảng 3.6. Các giá trị phản ảnh môi tương quan giữa glucose đói, HbA1C, và fructosamin

\begin{tabular}{|c|c|c|c|c|c|}
\hline \multirow{2}{*}{ Tương quan } & \multicolumn{2}{|c|}{ Phân tích hôi quy tuyến tính } & \multicolumn{2}{c|}{ Phân tích tương quan } \\
\cline { 2 - 6 } & $\mathbf{R}^{\mathbf{2}}$ & $\mathbf{R}$ & $\mathbf{P}$ & $\mathbf{r}$ & $\mathbf{p}$ \\
\hline Glucose đói với HbA1c trước điều trị & 0,1714 & 0,1258 & 0,003 & 0,4140 & 0,003 \\
\hline Glucose đói với Fructosamine trước điêu trị & 0,1437 & 0,1258 & 0,003 & 0,3790 & 0,007 \\
\hline Glucose đói với Fructosamine sau điêuu trị & 0,3445 & 0,3308 & $<0,001$ & 0,5869 & $<0,001$ \\
\hline
\end{tabular}

Nhận xét: kết quả phân tích cho thấy HbA1c và Fructosamin (lúc vào viện) đều có tương quan thuận mức độ vừa với glucose đói (lúc vào viện) với r lần lượt là 0,414 và 0,379 , mối liên quan là có ý nghĩa thống kê $(p<0,05)$. Hơn nữa, xét nghiệm fructosamin khi ra viện cũng thể hiện sự tương quan thuận ở mức độ khá ( $r=0,5869 ; p<0,001)$ với glucose đói (khi ra viện). 


\section{BÀN LUÂN}

Giá trị Fructosamine huyết thanh trong kiểm soát đường huyết ở bệnh nhân ĐTĐ type 2 . Để đánh giá tình trạng kiểm soát glucose máu ở bệnh nhân ĐTÐ thì phương pháp định lượng glucose máu và $\mathrm{HbA1C}$ thường được áp dụng phổ biến. Glucose máu phản ảnh chính xác nồng độ glucose máu tại thời điểm được lấy máu làm xét nghiệm, tuy nhiên lại thường dao động rất nhiều trong ngày, giữa các ngày khác nhau, và phụ thuộc vào nhiều yếu tố khác. Muốn đánh giá chính xác tình trạng glucose máu phải làm nhiêu lần xét nghiệm trong ngày. Hơn nữa glucose máu chỉ có giá trị tức thời nên rất khó đánh giá hiệu quả điều trị trong một giai đoạn, nhất là đối với bênh nhân điều tri ngoai trú mới điều trị lần đầu cần đánh giá hiệu quả điều trị sau 2 - 3 tuần. Ngược lại với giá trị glucose máu, HbA1C lại rất có giá trị trong việc đánh giá hiệu quả kiểm soát glucose trong khoảng thời gian $2-3$ tháng. Giá trị HbA1c cũng không phụ thuộc vào thời gian lấy máu. Tuy nhiên, trong một số trường hợp thì giá trị HbA1c không đáng tin cậy trong trường hợp mất cân bằng nội môi, bệnh lý về máu, bệnh thận mạn tính... Ngoài ra, để đánh giá hiệu quả điều trị trong một thời gian ngắn (2 -3 tuần) thì HbA1C không phù hợp Fructosamin là các cetoamin sản phẩm liên kết giữa Protein và glucose. Trong huyết thanh, Albumin chiếm tỷ lệ lớn nên việc định lượng fructosamin thực chất là định lượng Albumine glycosyl hóa. Tốc độ luân chuyển của Albumin trong máu trung bình trong khoảng 28 ngày, thời gian bán hủy $12-20$ ngày. Chính vì thời gian tồn tại trong máu ngắn hơn nhiều so với hồng câu nên đo giá trị fructosamin sẽ phản ánh giá trị glucose máu trung bình trong khoảng thời gian từ $1-3$ tuần trước đó. Đinh lương fructosamin giúp các thây thuốc lâm sàng đánh giá phác đồ điều trị trong thời gian sớm 1 - 3 tuần trong khi $\mathrm{HbA1c}$ phải đợi ít nhất 4 tuần mới thấy được sự cải thiện glucose máu. Điều này rất phù hợp trong đánh giá phác đồ kiểm soát glucose máu trong điều trị nội trú, những bệnh nhân ĐTÐ cao tuổi, ĐTĐ thai kỳ hay trong các trường hợp thiếu máu, các bệnh lý về máu khi mà chỉ số HbA1c không phản ảnh chính xác nồng độ glucose máu trung bình trong máu. Định lượng fructosamine ngoài việc theo dõi điều trị thì giá trị này còn giúp trong chẩn đoán bệnh đái tháo đường. Nồng độ fructosamin trong máu cao hơn giá trị tham chiếu xảy ra trong điều kiện glucose máu tăng dai dẳng, trùng hợp với tình trạng tăng glucose máu ở bệnh nhân ĐTĐ. Không thấy nồng độ fructosamin tăng lên khi bị stress giai đoạn ngắn (do kích thích) gây tăng glucose máu thoảng qua. Trong trường hợp này khoảng thời gian tăng đường huyết không đủ lâu để protein bị đường hóa. Như vậy, định lượng fructosamin có thể giúp phân biệt những trường hợp ĐTĐ thực sự với tình trạng tăng glucose máu nhất thời do stress. Trong nghiên cứu này, mức độ glucose máu, HbA1c, fructosamin lúc vào viện được sử dụng để đánh giá tình trạng kiểm soát lúc vào viện. Nồng độ glucose trung bình lúc ra viện, fructosamin được sử dụng để đánh giá hiệu quả kiểm soát đường huyết trong thời gian bệnh nhân được điều trị nội trú.

Trong 2 tuần điều trị trung bình, nồng độ glucose máu lúc đói, glucose máu sau ăn, và glucose máu trung bình giảm đáng kể tương ứng $9,0 \pm 4,4 \mathrm{mmol} / \mathrm{L}, 4,7 \pm 4,3 \mathrm{mmol} / \mathrm{L}, 6,8 \pm 3,3$ $\mathrm{mmol} / \mathrm{L}$ với các giá trị $\mathrm{p}<0,0001$. Nếu lấy tiêu chuẩn kiểm soát glucose theo tiêu chuẩn của Hội Nội tiết và Đái tháo đường Việt Nam thì $64 \%$ số đối tượng nghiên cứu không đạt mục tiêu kiểm soát glucose máu lúc đói, $32 \%$ số đối tượng nghiên cứu không đạt mục tiêu kiểm soát glucose máu sau ăn 2 tiếng. Căn cứ vào giá trị fructosamin cũng phản ảnh giảm đáng kể nồng độ glucose máu. Nồng độ fructosamin giảm trung bình khi vào viện và ra viện là $68,7 \pm$ $90,2 \mu \mathrm{mol} / \mathrm{L}(\mathrm{p}<0,0001)$. Phân tích kỹ hơn những đối tượng không được kiểm soát tốt đường huyết thì ngay chính những đối tượng có đường huyết lúc đói, sau ăn, fructosamin kiểm soát không tốt thì cũng có sự chênh lệch đáng kể giá trị khi vào viện và khi ra viện, tương ứng $9,0 \pm$ $4,4 \mathrm{mmol} / \mathrm{L}, 5,4 \pm 4,1 \mathrm{mmol} / \mathrm{L}$, và $68,7 \pm 90,2$ $\mu \mathrm{mol} / \mathrm{L}(p<0,001)$. Theo William và cộng sự [32], tác giả cũng nhận thấy sự sụt giảm đáng kể lượng fructosamin sau 2 tuần điều trị $(3.33 \pm$ $0.15 \mathrm{mM})$ và 3 tuần điều trị $(3.19 \pm 0.13 \mathrm{mM})$ so với lượng fructosamin ban đâu $(3.96 \pm 0.19 \mathrm{mM})$ trong khi sự giảm $\mathrm{HbA1c}$ sau 3 tuần điêu trị $(7.23 \pm 0.47 \%)$ so với tuần đầu tiên $(8.73 \pm$ 0.49) không có sự khác biệt. Tác giả Harn-Shen Chen tiến hành theo dõi đối tượng bênh nhân đái tháo đường từ tuần 1 đến tuần thứ 16 cũng đưa ra kết luận về mối tương quan manh mẽ giữa lượng đường ở 3 thời điểm là lúc đói, trước ăn và sau ăn với fructosamin từ tuần thứ 3 đến tuần thứ 6 , trong khi HbA1c có mối tương quan mạnh mẽ với lượng đường huyết từ tuần thứ 4 đển tuần thứ 12 đặc biệt lượng $\mathrm{HbA} 1 \mathrm{c}$ giảm mạnh ở tuần thứ 8 đển tuần thứ 10 . Điều này đã được khẳng định từ rất nhiêu nghiên cứu trên thế giới về vai trò của $\mathrm{HbA1c}$ phản ánh lượng 
đường huyết 2 đến 3 tháng và fructosamin phản ánh lượng đường huyết thời điểm ngắn hơn là 2 đến 3 tuần. Điều này gợi ý vai trò của fructosamin trong việc theo dõi hiệu quả điều trị bệnh trong thời gian ngắn. Hiện nay, các nhà nghiên cứu đang dần dần áp dụng định lượng chất được hình thành do quá trình glycosyl hóa albumin thay cho fructosamin (hình thành trong quá trình glycosyl hóa protein trong cơ thể nói chung) trong việc kiểm soát lượng đường máu khắc phục được nhược điểm của fructosamin do bị ảnh hưởng bởi nồng độ protein nói chung và các chất trọng lượng phân tử thấp trong huyết thanh như bilirubin, hemoglobin, acid uric. Điều này sẽ mở ra thêm nhiều chỉ số trong việc kiểm soát lượng đường máu sớm, giúp ích cho quá trình điều trị bệnh.

Đánh giá hiệu quả điều trị khi dùng giá trị glucose máu là thước đo và dùng fructosamin là thước đo cho thấy có sự đồng thuận cao giữa 2 phương pháp này với Kappa coeficient $=0,7748$

\section{KẾT LUÂN}

- Nồng đô glucose máu lúc đói, sau ăn, trung bình của các đối tượng nghiên cứu giảm

- Tỷ lệ đối tượng nghiên cứu đạt mục tiêu kiểm soát glucose máu lúc đói tăng rõ rệt sau thời gian nằm viện điều trị. Khi vào viện có $0 \%$ số đối tượng nghiên cứu có mức glucose máu lúc đói đạt mục tiêu kiểm soát glucose máu lúc đói, khi ra viện có $36,0 \%$ đối tượng nghiên cứu đạt mục tiêu kiểm soát glucóe máu lúc đói.

- Giá trị fructosamin trung bình khi ra viện thấp hơn nhiều khi vào viện trung bình 68,7 $\mu \mathrm{mol} / \mathrm{L}(360,6 \pm 69,9 \mu \mathrm{mol} / \mathrm{L}$ so với $429,3 \pm$ $62,2 \mu \mathrm{mol} / \mathrm{L})$ có ý nghĩ thống kê với $\mathrm{p}<0,0001$.

- Giá trị fructosamin trung bình khi ra viện thấp hơn nhiều khi vào viện trung bình 68,7 $\mu \mathrm{mol} / \mathrm{L}(360,6 \pm 69,9 \mu \mathrm{mol} / \mathrm{L}$ so với $429,3 \pm$ $62,2 \mu \mathrm{mol} / \mathrm{L})$ có ý nghĩ thống kê với $\mathrm{p}<0,0001$.

- Khi nhập viện, 100\% bệnh nhân không đạt mục tiêu kiểm soát đường máu dựa vào chỉ số fructosamin

- Mức fructosamin đạt mục tiêu kiểm soát lúc ra viện $30,0 \%$ so vớimức fructosamin đạt mục tiêu lúc nhập viện $0 \%$.

\section{TÀI LIÊU THAM KHẢO}

1. Danese E., Montagnana M., Nouvenne A. và cộng sự. (2015). Advantages and Pitfalls of Fructosamine and Glycated Albumin in the Diagnosis and Treatment of Diabetes. J Diabetes Sci Technol, 9(2), 169-176.

Committee, Sixth edition, pp. 11-37.

2. David K McCulloch, MD. Estimation of blood glucose control in diabetes mellitus. Literature review current through: Oct 2012. This topic last updated: Oct 25, 2012. ].

3. American Diabetes Association (2009), Standards of Medical Care in Diabetes-2011, Diabetes Care, 34 (1), pp. 11-61.

4. American Diabetes Association (2011), Standards of Medical Care in Diabetes-2013, Diabetes Care, 36 (1), pp. 11-66.

\section{MộT Số YẾU TỐ ẢNH HƯởNG ĐẾN ĐA THAI Ở BÊNNH NHÂN CHUYỂN PHÔI ĐÔNG LẠNH NGÀY BA}

\section{TÓM TẮT}

Đa thai là tình trạng thường gặp trong thu tinh trong ống nghiệm (TTTON). Nghiên cứu nhămm xác định một số yếu tố ảnh hưởng đến đa thai ở các bệnh nhân TiTON chuyển phôi đông lanh ngày 3 . Nghiên cứu mô tả hồi cứu ở 112 bệnh nhẩn đã trải qua chu kì thu tinh trong ống nghiêm tại trung tâm Hố trợ sinh sản và Công nghê̂ mô ghép, Bệnh viện Đại học Y Hà Nội tữ tháng $1 / 2018$ đến tháng $12 / 2020$. Các yếu tố thu được từ hai nhóm bệnh nhân chuyển 2 phôi và 3 phôi đồng lạnh ngày 3 được đưa vào phương trình hồi

${ }^{1}$ Trung tâm Hỗ trợ sinh sản và Công nghệ mô ghép, Bênh viên Đai hoc Y Hà Nôi

Chịu trách nhiệm chính: Trần Thị Phương Hoa

Email: drtranphuonghoa@gmail.com

Ngày nhân bài: 3.8.2021

Ngày phản biên khoa hoc: 29.9.2021

Ngày duyệt bài: 6.10.2021
Trần Thị Phương Hoa ${ }^{1}$, Nguyễn Mạnh Hà ${ }^{1}$

quy đa biến logistic để xác định các yếu tố nguy cơ của đa thai. Kết quả nghiên cứu cho thây, trong số 112 bệnh nhân xuất hiện ít nhất 1 túi thai sau chuyển phôi, tỷ lê đa thai chiếm $36 \%$. Khả năng xuất hiên đa thai ở nhóm chuyển 3 phôi cao gấp 1,685 lần nhóm chuyển 2 phôi. Tuổi me và chất lượng phôi chuyển cũng ảnh hưởng đễn sỗ lượng túi thai của bệnh nhân, tỷ lệ đa thai tăng ở nhóm tuối trẻ hơn $(37,4 \%$ ở nhóm $<35$ tuổi và $28,6 \%$ ở nhóm $\geq 35$ tuổi), khả năng xuất hiện đa thai ở nhóm chỉ có 1 phôi đô 1 hoăc độ 2 giảm 0,654 lần so với nhóm có 2 phôi đều là phôi độ 1 và độ 2 .

Từ khóa: Đa thai, Thụ tinh trong ống nghiệm, Chuyển phôi đông lạnh ngày 3.

\section{SUMMARY \\ FACTORS THAT INFLUENCE THE OCCURRENCE OF MULTIPLE PREGNANCIES AFTER FROZEN EMBRYO TRANSFER ON DAY 3}

